\title{
Evaluation of Vertical Ozone Profiles Simulated by WRF/Chem Using Lidar-Observed Data
}

\author{
Masanori Niwano ${ }^{1}$, Masayuki Takigawa ${ }^{1}$, Masaaki Takahashi ${ }^{1,2}$, Hajime Akimoto ${ }^{1}$, \\ Masahisa Nakazato ${ }^{3}$, Tomohiro Nagai ${ }^{3}$, Tetsu Sakai ${ }^{3}$, and Yuzo Mano ${ }^{3}$ \\ ${ }^{1}$ Frontier Research Center for Global Change, JAMSTEC, Yokohama, Japan \\ ${ }^{2}$ Center for Climate System Research, The University of Tokyo, Kashiwa, Japan \\ ${ }^{3}$ Meteorological Research Institute, Tsukuba, Japan
}

\begin{abstract}
We evaluated the ability of a regional air quality (AQ) model, the Weather Research and Forecast chemistry (WRF/Chem), to reproduce vertical profiles of summertime ozone $\left(\mathrm{O}_{3}\right)$ pollution over the Kanto region of Japan using lidar-observed $\mathrm{O}_{3}$ data collected over Tsukuba on 27-29 July and 16-21 August 2005. WRF/ Chem well reproduced the high $\mathrm{O}_{3}$ concentrations $>2.5$ $\times 10^{18}$ molec. $\mathrm{m}^{-3}(\sim 100 \mathrm{ppbv}$ below $1.5 \mathrm{~km}$ above sea level ASL) observed on 28 July and 20 August, and the low concentrations on the other days below $1.5 \mathrm{~km}$ ASL, as well as day-to-day variations above $1.5 \mathrm{~km}$ ASL. The formation mechanism of the observed $\mathrm{O}_{3}$ layer in the typical northward transport case on 28 July was also examined by the model. The $\mathrm{O}_{3}$ plumes entered the free troposphere through vertical transport and mixing near the sea breeze front and southward transport by the return flow in the afternoon. In the evening, the $\mathrm{O}_{3}$ layer formed at $0.7-1.5 \mathrm{~km}$ ASL possibly because of less transport between the sea breeze and return flow and longer photochemical lifetime than at the surface.
\end{abstract}

\section{Introduction}

Air quality (AQ) models have been developed to understand and forecast air pollution at regional scale (e.g., Uno et al. 2003) and global scale (Lawrence et al. 2003; Takigawa et al. 2005). To reproduce the ozone $\left(\mathrm{O}_{3}\right)$ and precursor distribution over the Kanto region of Japan (Fig. 1, inset) using an AQ model, fine-scale meteorology is important (Uno et al. 1996). Kimura (1985) showed that summertime $\mathrm{O}_{3}$ pollution episodes over the Kanto region occur in the rural inland portion through horizontal transport by the "extended" land-sea breeze coupled with mountain-valley winds as well as synoptic winds. Vertical transport and mixing by thermal convection and sea-breeze front updraft are also key factors in the surface $\mathrm{O}_{3}$ concentration. Dufour et al. (2005) clarified the multi-layered structure of $\mathrm{O}_{3}$ over southern France using lidar observation and used a model to examine the effect of the $\mathrm{O}_{3}$ layers on the surface concentration. Over Japan, some studies have conducted aircraft-based observations and have reported a multilayered structure of $\mathrm{O}_{3}$ (e.g., Wakamatsu et al. 1983). However, no previous studies have conducted quasicontinuous observations of vertical $\mathrm{O}_{3}$ profiles and evaluated models against the observations.

An AQ forecasting system has been developed based on the Weather Research and Forecast chemistry model (WRF/Chem) and the use of chemical boundary data from the CHASER model (Takigawa et al. 2007). We evaluated a hindcast experiment by WRF/Chem against vertical $\mathrm{O}_{3}$ profiles measured in summer 2005 by the recently developed lidar method (Nakazato et al. 2007).

Corresponding author: Masanori Niwano, Frontier Research Center for Global Change, JAMSTEC, Yokohama, 236-0001, Japan. E-mail: niwano@jamstec.go.jp. @2007, the Meteorological Society of Japan.

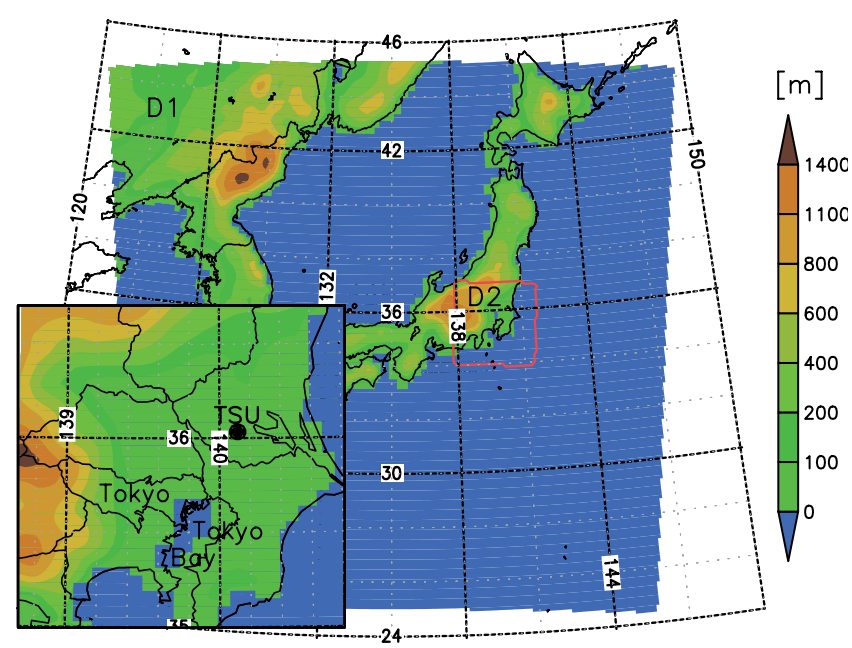

Fig. 1. Model domains (D1 and D2) and terrain height in $\mathrm{m}$ (coloring) for the regional CTM. Inset: Detailed map of the Kanto plain including D2 and the observation site, TSU: Tsukuba (black circle).

\section{Model and observation data}

The regional AQ model was the regional chemical transport model (CTM) WRF/Chem version 2.1.2 (Grell et al. 2005) and obtained lateral boundary data of chemical species from the global CTM CHASER (Sudo et al. 2002). The CHASER model was developed in the framework of the Center for Climate System Research/ National Institute for Environmental Studies/Frontier Research Center for Global Change (CCSR/NIES/ FRCGC) atmospheric general circulation model (AGCM) version 5.7b (Hasumi et al. 2004). Both WRF/Chem and CHASER calculate meteorology and chemistry "on-line," meaning that both the meteorological and chemical modules use the same time step, grid, and physics schemes. Takigawa et al. (2007) provided details of the model system.

The regional model consisted of two domains. The outer domain (D1) had $84 \times 84$ grids at $27-\mathrm{km}$ resolution, and the inner domain (D2) had $39 \times 39$ grids at $9-\mathrm{km}$ resolution (Fig. 1). Both domains had 30 layers from the surface to about $100 \mathrm{hPa}$ and approximately 11 layers below $2 \mathrm{~km}$. The planetary boundary layer (PBL) height and the vertical diffusion were calculated by the MellorYamada Level 2.5 model based on prognostic turbulent kinetic energy (Janjić et al. 2002). A hindcast experiment was conducted from 25 July to 23 August 2005, when lidar observations of $\mathrm{O}_{3}$ were conducted over Tsukuba (Fig. 1, black circle). For D1, boundary data for the meteorological field were from the three-hourly mesoscale model (MSM) analysis of the Japan Meteorological Agency (JMA). Simulated meteorological fields were updated by the MSM analysis at 09 Japanese Standard Time (JST $=$ Universal Time $+9 \mathrm{~h})$. The lateral 


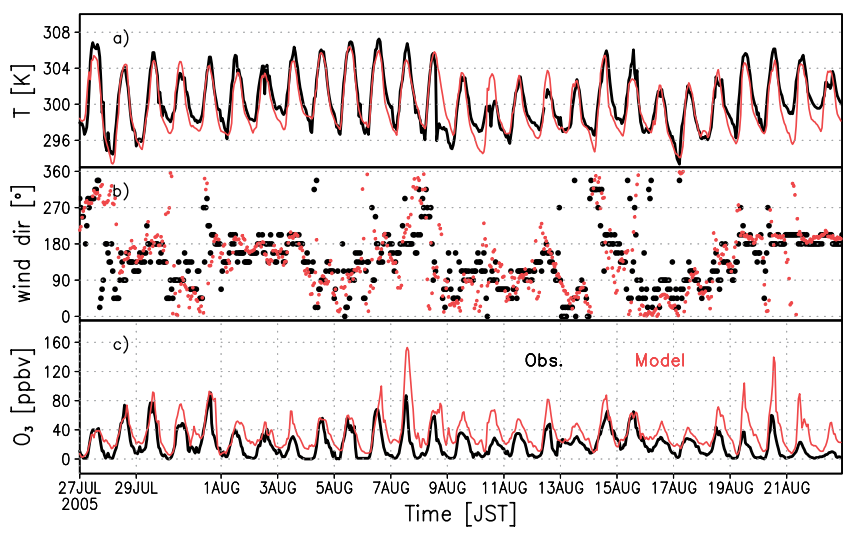

Fig. 2. Surface temperature in $\mathrm{K}$ (a), wind direction in degrees (b), and $\mathrm{O}_{3}$ mixing ratio in ppbv (c) at Tsukuba from the observation (black) and simulation (red) in July and August 2005.

boundary data of the chemical fields for D1 were obtained every $3 \mathrm{~h}$ from CHASER.

The simulated results were compared to vertical $\mathrm{O}_{3}$ measured by differential-absorption lidar (DIAL) at the Meteorological Research Institute (MRI) in Tsukuba $\left(140.10^{\circ} \mathrm{E}, 36.05^{\circ} \mathrm{N}\right)$ during the periods $27-29 \mathrm{July}$ and 16-21 August 2005. The data used were hourly data integrated for 30 min temporally and for $120 \mathrm{~m}$ vertically. This integration was sufficient to measure $\mathrm{O}_{3}$ concentration profiles from $400 \mathrm{~m}$ up to $10 \mathrm{~km}$ with estimated statistical errors $<5 \%$ at $1.5 \mathrm{~km}$ and $10 \%$ at $2.6 \mathrm{~km}$. Details of the $\mathrm{O}_{3}$ DIAL have been described by Nakazato et al. (2007). Data severely contaminated by clouds and aerosols were removed in advance using the following criteria: (1) if the estimated statistical errors were $>0.8$ $\times 10^{17}$ molec. $\mathrm{m}^{-3},(2)$ if the statistical errors were $>10 \%$, or (3) if the $\mathrm{O}_{3}$ concentration was $>3.5 \times 10^{18}$ molec. $\mathrm{m}^{-3}$. The obtained data were then interpolated to the same altitude levels as those of the WRF/Chem output data.

\section{Results and discussion}

To confirm the reproducibility of local meteorology and $\mathrm{O}_{3}$ concentration by WRF/Chem, observed and modeled time series at the surface level over Tsukuba were examined (Fig. 2). We focused on the periods of the DIAL measurement on 27-29 July and 16-21 August 2005. Tsukuba lies $60 \mathrm{~km}$ northeast of the Tokyo metropolitan region, and $\mathrm{O}_{3}$ plumes are typically carried from the Tokyo region in the "northward transport" case, when the extended southeasterly sea breeze co-occurs with weak southerly to southwesterly synoptic wind. The simulation on 28-29 July and 18-20 August represented a typical summertime $\mathrm{O}_{3}$ episode in the northward transport case in the Kanto area. The meteorological field at Tsukuba was representative of those at eastern Kanto region and showed less diurnal cycle of wind direction than in western Kanto region.

After the passing of Typhoon 200507 ("Banyan"), the surface temperature dropped (Fig. 2a), and easterly to southerly flow became dominant on 28 and 29 July (Fig. $2 \mathrm{~b})$ as a subtropical high over the Pacific Ocean covered Japan. On these two days, the modeled and observed $\mathrm{O}_{3}$ mixing ratios increased to nearly $80 \mathrm{ppbv}$ over Tsukuba and northern Kanto (Fig. 2c) in relation to the typical extended sea-breeze development. On 16 and 17 August, the surface temperature increased to at most $302 \mathrm{~K}$, and winds were northerly to easterly with light rain on 16 August, after a frontal low passed over Japan on 15 August. On these two days, the $\mathrm{O}_{3}$ mixing ratio was continuously low $(\sim 40 \mathrm{ppbv})$ for both the DIAL and model results. From 18 to 20 August, the tempera- ture gradually increased and southerly wind became dominant over the Kanto region as a subtropical high over the Pacific Ocean covered the Kanto region and a cold front approached over northern Japan. The observed $\mathrm{O}_{3}$ mixing ratio was at most 40 ppbv on 18 and 19 August and 60 ppbv on 20 August. The model well reproduced the $\mathrm{O}_{3}$ concentration increases on these three days, but overestimated those observed between 19 and 21 August. This overestimate was likely caused by the underestimate of convective cloud development and of consequent development of strong southerly convergence flow over northern Kanto in the afternoon. The observed strong southerly flow could have led to less accumulation of $\mathrm{O}_{3}$ in the southern Kanto region than in the model. During the whole period, the overall reproducibility of $\mathrm{O}_{3}$ was in accordance with the surface statistics over the Kanto region (normalized mean bias $[\mathrm{NMB}]=13.5 \%$ and correlation coefficient $r=0.71$ based on 268 stations with a threshold of $40 \mathrm{ppbv}$ ).

We next compared the observed and modeled vertical profiles of $\mathrm{O}_{3}$ concentration over Tsukuba. Plate 1 presents time-height sections of the $\mathrm{O}_{3}$ concentration over Tsukuba on 27-30 July and 16-22 August 2005. Below $1.5 \mathrm{~km}$ above sea level (ASL), the $\mathrm{O}_{3}$ concentration from the DIAL measurement (Plate 1a) showed dayto-day variation. On 28 July and 20 August, $\mathrm{O}_{3}$ concentrations $>2.5 \times 10^{18}$ molec. $\mathrm{m}^{-3}(\sim 100 \mathrm{ppbv}$ in the PBL) appeared below $1.5 \mathrm{~km}$ ASL from around noon. The layered structure on 28 July at $0.5-1.5 \mathrm{~km}$ ASL remained until 03 JST on 29 July. From 16 JST on 19 August to 06 JST on 20 August, a layered structure of $\mathrm{O}_{3}$ concentration of $\sim 1.25 \times 10^{18}$ molec. $\mathrm{m}^{-3}$ was observed. On 17 and 21 August, there was little enhancement $>2.0 \times 10^{18}$ molec. $\mathrm{m}^{-3}$ in the DIAL data. The modeled $\mathrm{O}_{3}$ (Plate $1 \mathrm{~b}$ ) compared well to the observed enhancement on 28 July and 20 August and to the low enhancement on 17 August. The model succeeded in well reproducing the observed nocturnal layered structure over the Kanto region on 28-29 July and 19-20 August for the first time. The statistical analysis of the time series of $\mathrm{O}_{3}$ concentration from the DIAL and from the model during these periods indicated relatively good results $(\mathrm{NMB}=7.82 \%$ and $r=0.48$ at $1.0-1.5 \mathrm{~km}$ ASL). The relatively small $r$ mainly arose from the overestimation of $\sim 0.5 \times 10^{18}$ molec. $\mathrm{m}^{-3}$ for 16-21 August.

Above $1.5 \mathrm{~km}$ ASL, the DIAL $\mathrm{O}_{3}$ concentration (Plate 1a) became $>1.25 \times 10^{18}$ molec. $\mathrm{m}^{-3}$ from 27 to $28 \mathrm{July}$ and $>1.0 \times 10^{18}$ molec. $\mathrm{m}^{-3}$ on 17 August, whereas it remained $<1 \times 10^{18}$ molec. $\mathrm{m}^{-3}$ from 19 to 21 August. The model (Plate 1b) successfully captured the observed temporal variations with enhancement on 27-28 July and 17 August and without enhancement on 19-21 August over Tsukuba $(r=0.61-0.74$ at $2.5-4.5 \mathrm{~km}$ ASL during these periods). In contrast, the model continuously underestimated the mean $\mathrm{O}_{3}$ concentration at this altitude range $(\mathrm{NMB}=-21.9 \%$ at $2.5-3.5 \mathrm{~km}$ ASL and $30.9 \%$ at $3.5-4.5 \mathrm{~km}$ ASL during these periods). The combination of the overestimation below $1.5 \mathrm{~km}$ ASL and underestimation above $1.5 \mathrm{~km}$ ASL implies that vertical mixing in the PBL was underestimated. Kim et al. (2006) obtained similar results in a study involving WRF/ Chem evaluation over the United States. They reported overestimates of $\mathrm{O}_{3}$, carbon monoxide, and nitrogenous species below $1-1.5 \mathrm{~km}$ and underestimates above $1-1.5$ $\mathrm{km}$. The underestimate of vertical mixing in the MellorYamada level 2.5 closure model should be addressed, as noted by several previous studies (e.g., Nakanishi and Niino 2004). The improvement of the vertical mixing calculation would reduce the overestimate of the PBL $\mathrm{O}_{3}$ concentration that was found during the periods that we described. However, the underestimate above $1.5 \mathrm{~km}$ ASL is considered to be more related to the underestimate of the time mean $\mathrm{O}_{3}$ and precursor concentrations of the lateral boundary data from CHASER because the negative NMB increases with height. The inclusion of updated emission inventory and time-dependent hot- 


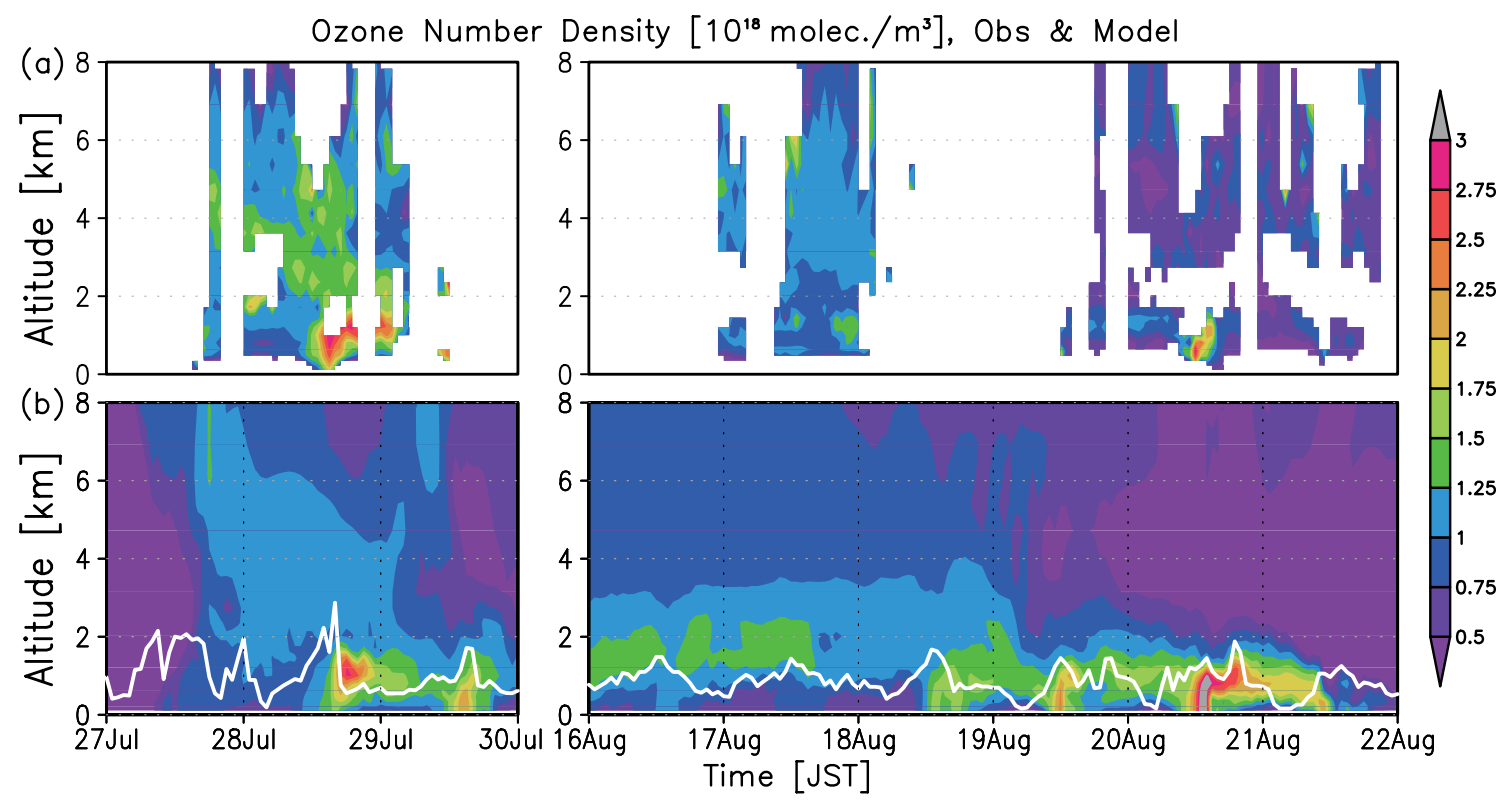

Plate 1. Time-height sections of the $\mathrm{O}_{3}$ concentration in $1 \times 10^{18}$ molec. $\mathrm{m}^{-3}$ ( $\sim 40$ ppbv) over Tsukuba from the $\mathrm{O}_{3}$ DIAL measurement (a) and the model (b). The PBL height (white line) is also plotted in (b). The DIAL data are based on hourly data integrated for 30 min, while the simulated data are hourly instantaneous values. Blanks in the DIAL data indicate that data were removed by quality controls or no observation occurred at that time.

spot data would help to reduce the underestimate above $1.5 \mathrm{~km}$ ASL during these periods. Model evaluations using longer-term DIAL data are needed to obtain more precise results.

To confirm the reproducibility of horizontal distributions by the model, we examined horizontal maps of the wind direction and $\mathrm{O}_{3}$ mixing ratio at 16 JST on 28 July and 17 August from the observations and model (Fig. 3). The DIAL measured an $\mathrm{O}_{3}$ plume on $28 \mathrm{July}$ over Tsukuba, but not on 17 August (Table 1a). At 16 JST on 28 July, the wind direction was generally southerly at $139-140^{\circ} \mathrm{E}, 35-36.5^{\circ} \mathrm{N}$ (Fig. 3a), and $\mathrm{O}_{3}$ plumes were detected north of the Tokyo area by both the observations and the model (Fig. 3c). At 16 JST on 17 August, the observations and model indicated southeasterly flow over the Kanto area (Fig. 3b) and $\mathrm{O}_{3}$ plumes southwest of the Tokyo area (Fig. 3d). For both days, WRF/Chem generally simulated the horizontal distributions of wind direction and $\mathrm{O}_{3}$, although the model missed the $\mathrm{O}_{3}$ plumes north of $36.2^{\circ} \mathrm{N}$ on 28 July because of the delay of sea breeze onset.

The formation processes of the $\mathrm{O}_{3}$ layer in the typical northward transport case of 28 July were also investigated using WRF/Chem. The $\mathrm{O}_{3}$ concentration, meridional and vertical winds, and PBL height averaged over $139.7-140.2^{\circ} \mathrm{E}$, an area that includes Tsukuba, are shown in Fig. 4. Northerly and southerly winds were dominant and the $\mathrm{O}_{3}$ distributions were longitudinally homogeneous over this area on this day. At 12 JST (Fig. $4 \mathrm{a}$ ), an $\mathrm{O}_{3}$ mixing ratio of $70-80 \mathrm{ppbv}$ and large vertical motions appeared at $35.5-36.8^{\circ} \mathrm{E}$ (corresponding to the Tokyo Bay area) below $1 \mathrm{~km}$ ASL, indicating vertical transport of $\mathrm{O}_{3}$ and its precursors and photochemical production of $\mathrm{O}_{3}$ from its precursors. At 16 JST (Fig. 4b), high $\mathrm{O}_{3}$ mixing ratios $>100$ ppbv appeared over 35.4$36.1^{\circ} \mathrm{N}$ up to $1.5 \mathrm{~km}$ ASL. Upward motion up to $1.7 \mathrm{~km}$ ASL and northerly return flow at $1.5-3 \mathrm{~km}$ occurred south of the sea breeze front at $36^{\circ} \mathrm{N}$. PBL heights were $1.5-2.5 \mathrm{~km}$ ASL north of the sea breeze front and $0.5-1$ $\mathrm{km}$ south of the front, with a large gap around the front. Consistently, the sea breeze layer was relatively cold and stable, whereas the northern regions and the front region were well heated and highly diffusive (not shown). These results suggest that the $\mathrm{O}_{3}$ plumes were

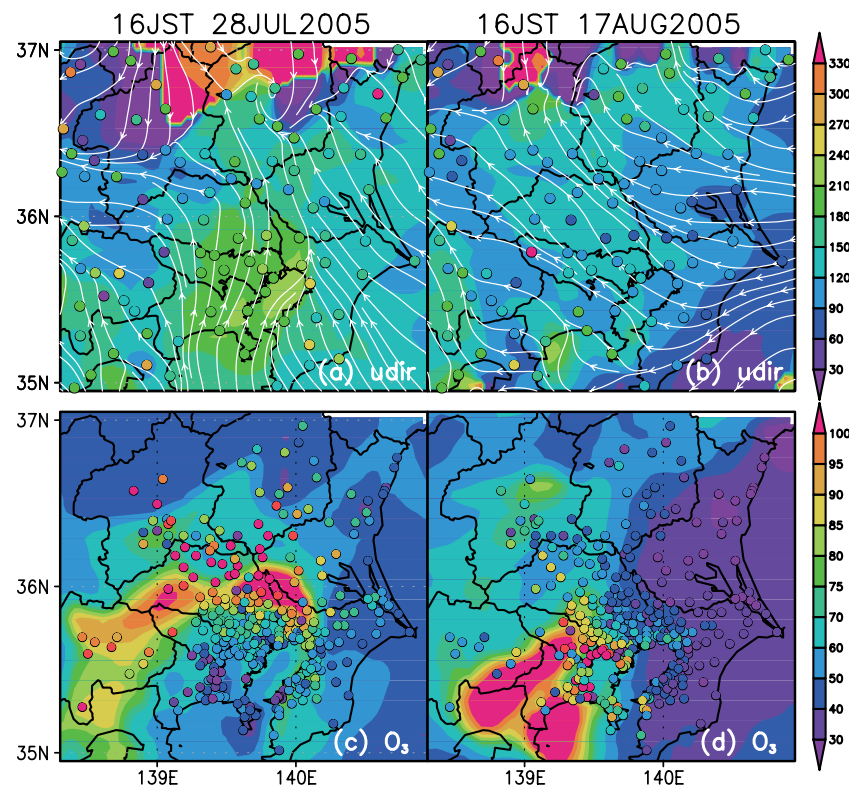

Fig. 3. Horizontal maps of wind direction in degrees (a and b) and the $\mathrm{O}_{3}$ mixing ratio in ppbv (c and d) near the surface level from the observation (circles) and the model (coloring) at 16 JST on 28 July ( $a$ and $c$ ) and 17 August (b and d). Stream lines from the model are indicated by white lines ( $a$ and $b)$.

transported upward by the vertical advection and mixing around the sea breeze front and southward by the return flow into the free troposphere. Thus, the sea breeze likely plays a role in venting $\mathrm{O}_{3}$ plumes into the free troposphere. At 20 JST (Fig. 4c), the extended sea breeze covered the whole region below $1 \mathrm{~km}$ ASL and northerly return flow occurred north of $36.3^{\circ} \mathrm{N}$ above $1.5 \mathrm{~km}$ ASL. Between the sea breeze and its return flow, $\mathrm{O}_{3}$ plumes of $>100 \mathrm{ppbv}$ were detected at $0.7-1.5 \mathrm{~km}$ ASL. At 00 JST on 29 July (Fig. 4d), the sea breeze below $1.3 \mathrm{~km}$ ASL and the $\mathrm{O}_{3}$ plumes of $>80$ ppbv at $0.7-1.5$ 


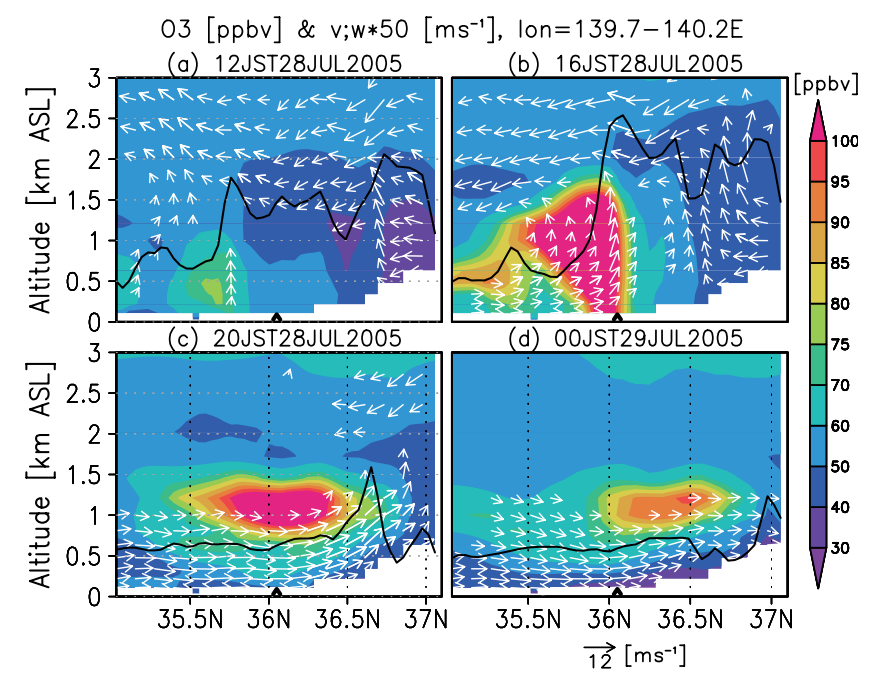

Fig. 4. Latitude-altitude sections of the $\mathrm{O}_{3}$ mixing ratio in ppbv (coloring), meridional and vertical wind fields in $\mathrm{m} \mathrm{s}^{-1}$ (horizontal and vertical arrows), and PBL heights (black lines) averaged over $139.7-140.2^{\circ} \mathrm{E}$ from the model at 12 JST (a), 16 JST (b), and 20 JST on 28 July (c), and 00 JST on 29 July (d). Unit vector length of $12 \mathrm{~m} \mathrm{~s}^{-1}$ is shown at the bottom of the figures, and vertical winds are multiplied by fifty. Wind vectors are drawn for meridional wind speed $>3 \mathrm{~m} \mathrm{~s}^{-1}$ or vertical wind speed $>3$ $\mathrm{cm} \mathrm{s}^{-1}$. The location of Tsukuba is indicated by triangles.

$\mathrm{km}$ still remained. Using aircraft observations, Wakamatsu et al. (1983) found a similar $\mathrm{O}_{3}$ layer around $0.5 \mathrm{~km} \mathrm{ASL}$ in a land breeze area northwest of Tokyo Bay in the morning. They suggested that the $\mathrm{O}_{3}$ layer was caused by old pollution that was trapped overnight by the back-and-force movement of the land-sea breeze. Our results indicate that the nocturnal $\mathrm{O}_{3}$ layer between 0.7 and $1.5 \mathrm{~km}$ ASL was caused by less transport in the weak wind layer and longer lifetime of $\mathrm{O}_{3}$ than at the surface. The extended sea breeze in the Kanto region has a spatial scale of $100 \times 100 \mathrm{~km}$, an amplitude of $3 \mathrm{~m}$ $\mathrm{s}^{-1}$, and a depth of $>1.5 \mathrm{~km}$, making it a larger than normal coastal land-sea breeze, which usually has a spatial scale of $20-40 \mathrm{~km}$, amplitude of $1 \mathrm{~m} \mathrm{~s}^{-1}$, and depth of $1 \mathrm{~km}$. Similar extended land-sea breezes have been identified in California and Korea. We suggest that the venting effect of such extended sea breezes is at least 10 times greater than those of normal breezes based on the typical values noted above.

\section{Conclusion}

We evaluated the performance of an "on-line" regional model WRF/Chem for summertime episodes of $\mathrm{O}_{3}$ pollution over the Kanto region of Japan using DIALobserved $\mathrm{O}_{3}$ data measured over Tsukuba on 27-29 July and 16-21 August 2005. Below $1.5 \mathrm{~km}$ ASL, the $\mathrm{O}_{3}$ concentration determined using both the DIAL and model showed enhancement $>2.5 \times 10^{18}$ molec. $\mathrm{m}^{-3}(\sim 100$ ppbv) on 28 July and 20 August and little enhancement on the other days. Above $1.5 \mathrm{~km}$ ASL, day-to-day variations were well reproduced by the model, whereas the $\mathrm{O}_{3}$ concentration was generally underestimated by 20$30 \%$ during this period. Model evaluations using DIAL data measured over longer periods should be conducted to obtain more precise results. The formation mechanism of the observed $\mathrm{O}_{3}$ layer was examined for a typical northward transport case on 28 July using the model. The $\mathrm{O}_{3}$ plumes were transported into the free troposphere by vertical advection and mixing near the sea breeze front and by return flow in the afternoon. In the evening, the $\mathrm{O}_{3}$ layer formed at $0.7-1.5 \mathrm{~km}$ ASL in the weak wind layer between the sea breeze and return flow, possibly because of less transport and longer photochemical lifetime than at the surface.

\section{Acknowledgments}

We thank Dr. G. A. Grell, Prof. K. Sudo, and other colleagues who developed the WRF/Chem and CHASER models. We also acknowledge those engaged in the observations at the air quality monitoring stations. This work has been supported by an internal special project fund of the Japan Agency for Marine-Earth Science and Technology (JAMSTEC).

\section{References}

Dufour, A., M. Amodei, G. Ancellet, and V.-H. Peuch, 2005: Observed and modelled "chemical weather" during ESCOMPTE, Atmos. Res., 74, 161-189.

Grell, G. A., S. E. Peckham, R. Schmitz, S. A. McKeen, J. Wilczak, and B. Eder, 2005: Fully coupled "online" chemistry within the WRF model. Atmos. Environ., 39, 6957-6975.

Hasumi, H., S. Emori, A. Abe-Ouchi, and co-authors, 2004: K-1 coupled GCM (MIROC) description. Technical Report, CCSR, Kashiwa, Chiba, Japan.

Janjić, Z. I., 2002: Nonsingular implementation of the MellorYamada level 2.5 scheme in the NCEP meso model, NCEP Office Note, 437, $61 \mathrm{pp}$.

Kim, S.-W., S. A. McKeen, E.-Y. Hsie, M. K. Trainer, G. J. Frost, G. A. Grell, and S. E. Peckham, 2006: The influence of PBL parameterizations on the distributions of chemical species in a mesoscale chemical transport model, WRF-Chem, Extended Abstract of the 17 th Symposium on Boundary Layers and Turbulence, 22-25 May, San Diego, California.

Kimura, F., 1985: A numerical simulation of local winds and photochemical air pollution (II): Application to the Kanto Plain, J. Meteor. Soc. Japan, 63, 923-935.

Lawrence, M. G., P. J. Rasch, R. von Kuhlmann, and co-authors, 2003: Global chemical weather forecasts for field campaign planning: predictions and observations of largescale features during MINOS, CONTRACE, and INDOEX, Atmos. Chem. Phys., 3, 267-289.

Nakanishi, M., and H. Niino, 2004: An improved Mellor-Yamada level 3 model with condensation physics: its design and verification. Bound.-Layer Meteor., 112, 1-31.

Nakazato, M., T. Nagai, T. Sakai, and Y. Hirose, 2007: Tropospheric ozone differential-absorption lidar using stimulated Raman scattering in carbon dioxide, Appl. Opt., 46, 2269-2279.

Sudo, K., M. Takahashi, and H. Akimoto, 2002: CHASER: a global chemical model of the troposphere 1. Model description. J. Geophys. Res., 107, doi:10.1029/2001JD 001113.

Takigawa, M., M. Niwano, H. Akimoto, and M. Takahashi, 2007: Development of a one-way nested global-regional air quality forecasting model, SOLA, 3, 81-84.

Takigawa, M., K. Sudo, H. Akimoto, K. Kita, N. Takegawa, Y. Kondo, and M. Takahashi, 2005: Estimation of the contribution of intercontinental transport during the PEACE campaign by using a global model, J. Geophys. Res., 110, D21313, doi:10.1029/2005JD006226.

Uno, I., G. R. Carmicahel, D. G. Streets, and co-authors, 2003: Regional chemical weather forecasting system CFORS: model descriptions and analysis of surface observation at Japanese island stations during the ACE-Asia experiment, J. Geophys. Res., 108(D23), 8668, doi:10.1029/2002JD 002845 .

Uno, I., T. Ohara, and S. Wakamatsu, 1996: Analysis of wintertime $\mathrm{NO}_{2}$ pollution in Tokyo metropolitan Area, Atmos. Environ., 30, 703-713.

Wakamatsu, S., Y. Ogawa, K. Murano, K. Goi, and Y. Aburamoto, 1983: Aircraft survey of the secondary photochemical pollutants covering the Tokyo metropolitan area, Atmos. Environ., 17, 827-835.

Manuscript received 20 September 2007, accepted 10 December 2007 SOLA: http://www.jstage.jst.go.jp/browse/sola/ 